\title{
Evaluation of Bioactive Traits of Eclipta alba (L.) Hassk. Root Exudates
}

\author{
Nabanita Chakraborty ${ }^{1}$, Soma Rani Patra² and Suparna Mandal \\ Biswas $^{1 *}$
}

${ }^{1}$ Agricultural and Ecological Research Unit, Indian Statistical Institute, 203, B. T. Road, Calcutta 700108, INDIA

${ }^{2}$ Department of Biotechnology, Gitam Institute of Science, Gitam University, Visakhapatnam 530045

\begin{abstract}
Eclipta alba (L.) Hassk (Asteraceae) is a branched herbaceous plant known for its curative properties against various tropical and sub-tropical diseases. In India, it is commonly known as Bhringaraj and Karisilakanni and in Bengali it is called keshut. The extensive growth of the plant in moist areas of diverse topology indicates its invasiveness and signifies its intense allelopathic activity. Morphologically the plant bears soft and sessile stem. In view of this allelopathic potential, the roots of the plants are considered as a vital biochemical mediator to the environment. Hence, the present study attempts to evaluate the allelopathic activity of the root exudates of $E$. alba. Amongst the major solvent extracts from the roots, the methanol fraction was found to possess significant antimicrobial activity against microbes with multiple hosts and environment. Bioassay on crop germination establishes it as a natural agricultural resource for fertilizer. The experimental finding inferred statistical significance at 0.001 level and validates practical implication.
\end{abstract}

Key words: Allelochemical, Antimicrobial activity, Bioassay, Eclipta alba, Root exudates.

Correspondence : S. M. Biswas Address: Agricultural and Ecological Research Unit, Indian Statistical Institute, 203, B. T. Road, Calcutta 700108, India Tel:(+91)(033)25753225 Fax:(+91)(033)25753049 Email: suprana@isical.ac.in

DOI: 10.32945/atr3714.2015 


\section{INTRODUCTION}

Allelochemicals generally refer to the secondary metabolites released by intact living plants into their surroundings (Rice, 1984; Dayan et al., 2000; Einhelling, 2004). These metabolites exert inhibitory or stimulatory effects on other plants, fungi, bacteria among others in the environment including the rhizosphere. Hence, they form vital plant-based agricultural sources of flavonoids, tannins, alkaloids and aromatic acids that have been observed to be active against weeds, pathogens, and insects (Inderjit, 1996; Duke et al., 2000). They also play a role in plant defense mechanisms.

The current trend demands agricultural practices to be bio-intensive. Safeguarding the environment is a major concern because continuous and injudicious use of synthetic products have led to problems such as diminishing resistance to pathogens, accumulation of residual toxic chemicals leading to contamination of food and environment, and undesirable effects on biota. The use of natural agrochemicals in order to develop safe and compatible environment-friendly approach has gained increasing attention. Natural agrochemicals reduce the input of synthetic chemicals and help to conserve natural fauna. These are effective and often quickly biodegradable, and hence present no threat of toxic residue. Strong bioactive allelochemicals are a source of biological herbicides and fungicides (Inderjit and Mukerji, 2006). Such biopesticides can replace commercial pesticides that spell hazards (Khanh etal., 2005).

This paper attempts to elucidate the allelopathic analysis of a common world wide invasive weed, E. alba (L.) Hassk (Asteraceae) (Figure 1) ascending up to a maximum length of $6 \mathrm{ft}$. In India, E. alba (L.) Hassk is generally distributed in areas of gangetic planes, pasture lands, road sides, marshes, rivers, lakes, and on the foot hills of the Himalayas (Mithun and Shashidhara, 2011). This herbaceous weed is used in Ayurveda and Yunani medicinal formulations. According to Ayurveda philosophy, Eclipta is bitter, hot fattening, alterative, anthelminticum, and alexipharmic. It is useful in the treatment of inflammations, hernia, eye diseases, bronchitis, asthama, leucoderma, anaemia, heart and skin diseases, right blindness, syphilis among others. It is reported as beneficial for skin, hair, eyes, and teeth. Apart from their medicinal value, this plant shows wide and dense distribution at different environmental conditions suggesting that it has potential allelopathic effects. Most of the research works have been done on its pharmacological properties, but allelopathic activity of the plant mediated through its roots is less explored. E. alba is entirely a soft and 
sessile herb, so its allelopathic effects are mainly mediated through root exudates. In the present study, the allelopthic effects from root exudates of E. alba plant are given emphasis.

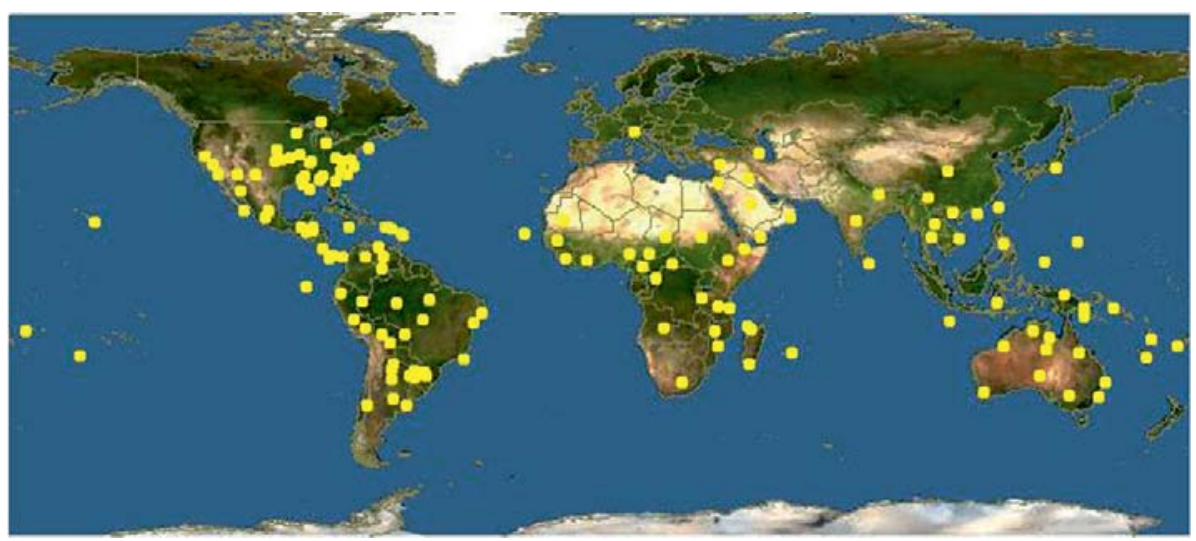

Figure 1. Geographical distribution of Eclipta alba, L. Hassk.

Source:http://www.discoverlife.org/nh/maps/Plantae/Dicotyledoneae/Astera ceae/Eclipta/map_of_Eclipta_alba.jpg

\section{MATERIALS AND METHODS}

\section{Collection of Root Exudates}

Root exudates of $E$. alba were collected after growing in RE-trapping systems made with a $110 \mathrm{~mm}$-diameter Buchner funnel and conical flasks of $500 \mathrm{ml}$ capacity (Figure 2). The central part (sieve portion) of the funnel was removed and the funnels were filled with sterilized soil collected from the field. Initially, a small piece of muslin cloth was placed at the lower portion of the funnel to hold the soil in. The funnels were kept on conical flasks that were painted black and contained distilled water. Five to seven germinated seeds of E. alba from which RE were to be obtained, were sown in each funnel. Thinning was done, and one to four plants depending upon the growth or size of the plants, were allowed to grow. After the plants attained the age of 20-25 days, plant roots penetrated the soil of the Buchner funnels and emerged into the conical flasks containing distilled water. RE was then collected regularly from the conical flasks at an interval of 5-7 days for 2 to 3 months; the conical flasks were filled immediately with fresh distilled water. 


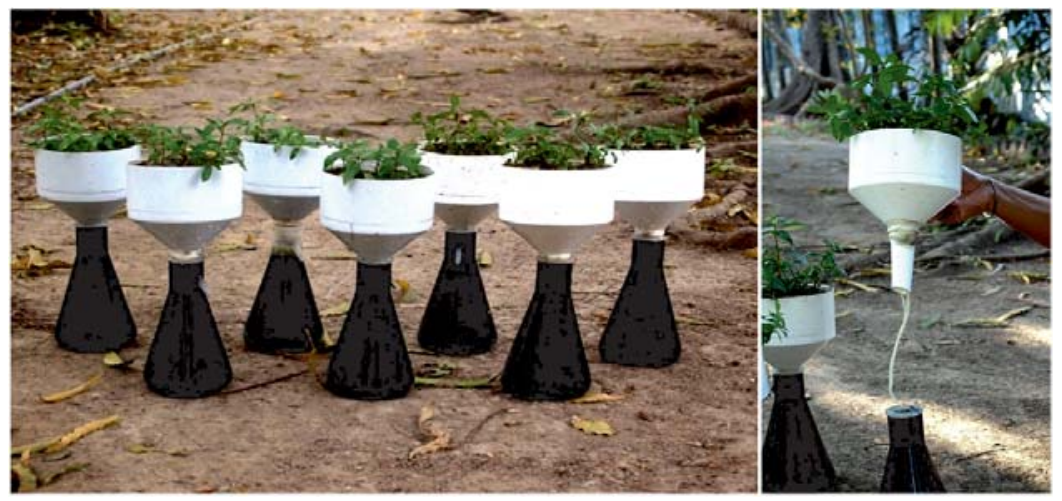

Figure 2. Root Exudates Trapping System of Eclipta alba L. Hassk.

Isolation and Characterization of Active Compounds from the Root Exudates

The collected REs of E. alba were evaporated under reduced pressure at $50^{\circ} \mathrm{C}$ by RVE and then extracted with solvents of different polarities. Finally, the compounds were purified by column chromatography and thin layer chromatography (TLC). Compounds were recovered mainly from methanol and water fractions. However, bioactive allelochemicals were recovered from the methanol fraction; so, we placed emphasis on the methanol fraction of Eclipta alba (henceforth referred to as MFEA).

\section{Column Chromatography}

Columns $(38 \times 4 \mathrm{~cm})$ were tightly packed with Silica gel with three different mesh sizes (60-120,100-200, and 230-400 mesh) up to $25 \mathrm{~cm}$. The material coated silica gel was poured over it. Column was then run with different solvent systems starting with the non-polar system consisting of ethyl acetate:hexane $(3: 2 \mathrm{v} / \mathrm{v})$ followed by the polar solvent system of acetone:methanol (9.5:0.5 v/v). Fractions collected at different time intervals were subjected to TLC analysis.

\section{Thin Layer Chromatography}

Plates $\left(20 \times 14 \mathrm{~cm}^{2}\right)$ were coated uniformly with $0.5 \mathrm{~mm}$ thick layer of Silica gel $\mathrm{G}$ and added with $20 \mu \mathrm{l}$ of the fraction $(500 \mathrm{ppm})$ by $25 \mu \mathrm{l}$ micropipette and developed up to $18 \mathrm{~cm}$ in glass chamber pre-saturated with mobile phase Ethyl acetate : Hexane (60:40v/v). Finally, 
the compound was detected by exposing the loaded plates under UV light and under iodine vapor. Our compounds of interest are highly methanol soluble and was confirmed by Rf value in the above mentioned solvent system.

\section{Antifungal Assay of MFEA}

Inhibition zone test technique was performed for testing the antifungal activity impact of extracted methanol fraction of $E$. alba against four different fungal species viz. Aspergillus niger, A. tamarii, A. fumigates and Rhizopus sporangia. Few fungal spores of the test fungi were transferred to PDA (Potato Dextrose Agar Media) slants and incubated for one week for colony growth. After one week, one loop full of fungal spore of each species was added separately to the sterile saline water and was mixed well. Fungal spore suspension $(1 \mathrm{ml})$ in water was then poured in a sterile petri dish containing molten PDA and allowed to solidify. Four cups $\left(25 \mathrm{~mm}^{2}\right.$ sizes $)$ were cut at equidistant positions and with $0.5 \mathrm{ml}$ of purified Fraction- 4 at $500 \mathrm{ppm}, 1000 \mathrm{ppm}, 1500 \mathrm{ppm}$, and $2000 \mathrm{ppm}$. Treated plates were incubated at $28 \pm 1^{\circ} \mathrm{C}$ for $24-48 \mathrm{hrs}$. Thereafter, colony growth inhibition was observed and recorded; 48 hrs plates were taken out; and observations were recorded for colony growth inhibition. Area of inhibition zone was calculated using the equation (Biswas et al., 2009b):

Area of inhibition at $\mathrm{xppm}=3.14\left\{(\mathrm{TRx})^{2}-(\mathrm{r})^{2}\right\}$

Where: $\mathrm{x}=$ concentration used, $\mathrm{r}=$ radius of the cup area, $\mathrm{TR}=$ Total radius of the inhibition zone at specific concentration (Biswas et al, 2009b).

\section{Antibacterial Assay of MFEA}

The effects of methanol fraction of E. alba were detected by inhibition zone test on several gram-positive, and gram-negative bacteria such as Escherichia coli, Streptococcus aureus and Pseudomonas aeruginosa were evaluated by inhibition zone test. Firstly, the strains of test bacteria were transferred to NA (Nutrient Agar) slants and incubated for $24 \mathrm{hrs}$. Then, 1 loop full of bacterial spore of each test species was added separately to sterile nutrient broth, mixed well, and incubated at $37^{\circ} \mathrm{C}$ for 150 minutes. Bacterial spore suspension $(1 \mathrm{ml})$ in sterile nutrient broth 
was then added to sterile petri dish containing molten NA medium and allowed to solidify. After complete solidification, four cups ( $25 \mathrm{~mm}^{2}$ sizes) were cut at equidistant positions. A $0.5 \mathrm{ml}$ of solution of purified Fraction-4 at $500 \mathrm{ppm}, 1000 \mathrm{ppm}, 1500 \mathrm{ppm}$, and $2000 \mathrm{ppm}$ was added to each cup. Treated plates were incubated at $37 \pm 1^{\circ} \mathrm{C}$ for $24 \mathrm{hrs}$. Then, the inhibition zone was measured and recorded. Area of inhibition zone was calculated using the same formula for fungal effects.

Effects of Methanol Fraction of E. alba at Different Concentrations on the Germination and Subsequent Growth of Rice

The allelopathic potentials of isolated and purified methanol fraction of $E$. alba on the germination and seedling growth of rice were determined by bioassay experiments. At 2000 ppm stock solution of MFAE (300 mg in $150 \mathrm{~mL}$ distilled water) was prepared from which dilute solutions of 1800 , $1600,1400,1200,1000,800,600,400$, and 200 ppm were made.

In one experiment, eleven sets of petridish bioassay including control were performed. The experiment was replicated thrice. For the control, $15 \mathrm{ml}$ of distilled water was added instead of the test solution. Seeds were surface-sterilized with $0.1 \%$ mercuric chloride solution, washed with distilled water, and placed in petri dishes lined with filter paper. After 4 days, shoot length and root length in the control and treated sets were measured (Mandal, 2001).

\section{Statistical Analysis}

Statistical analysis was performed using SPSS software: Version 20. The results were presented as the mean \pm S.D. Descriptive statistics of all the variables was done to see significant changes in mean of shoot length and root length of rice seeds as exhibited by different concentrations of MFEA. One-way analysis of variance (ANOVA) followed by Scheffe were applied to see the effects of MFEA at different concentrations on dependent variables with the level of significance set at $\mathrm{P} \leq 0.01$.

\section{RESULTS}

Yield (\%) of RE

Nearly 10 litres of RE of E. alba were collected throughout the season from the 12 sets of RE-trapping systems. Approximately 5-5.5 gm dried root exudates were recovered after evaporation. 
Isolation and Characterization of Active Allelochemical

Results on the isolation and characterization of active allelochemical obtained from concentrated RE, extracted with solvents of different polarities are shown in the Flow Diagram. Major compounds were recovered from the methanol fraction and few compounds from the water fraction. By repeatedly following the proposed scheme of fractionation, we could extract the compound of interest, MFEA, as a single pure compound (purity $>95 \%$ ). At least eight repetitions of the procedure were necessary to achieve this.

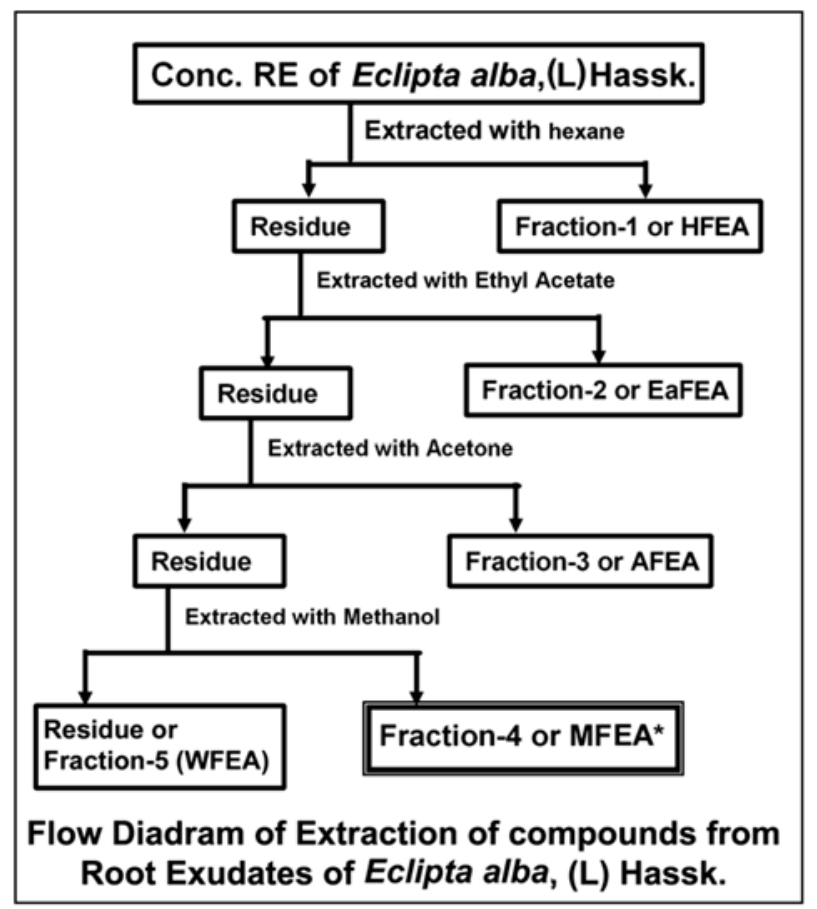

Column Chromatography Analysis

Five different fractions were collected by column run and 3-3.5 gms of MFEA was recovered from the fourth fraction. Purified MFEA is yellowish brown in colour and viscous at room temperature. 
Evaluation of Bioactive Traits of Eclipta alba (L.) Hassk. Root Exudates

\section{TLCanalysis}

Thin Layer Chromatography using ethyl acetate:hexane (60:40 v/v) solvent gave a single bright silver fluorescent spot under UV light at $365 \mathrm{~nm}$ and a deep black spot in iodine vapor with Rf value of 0.27 .

Antifungal Assay of MFEA

The methanol fraction of E. alba (MFEA) showed concentration dependent inhibitory activity on four dermatological significant fungal species (Figure 3). Rhizopus sporangia and Aspergillus fumigates were much more sensitive to MFEA than $A$. niger and $A$. tamari. The maximum inhibition of $A$. fumigatus and $R$. sporangia were observed at $1000 \mathrm{ppm}$ with IZD of $30 \mathrm{~mm}$ and $28 \mathrm{~mm}$, respectively. In the case of $A$. niger, maximum inhibition was obtained at 500ppm with IZD of $24 \mathrm{~mm}$ whereas in A. tamari, was at $1500 \mathrm{ppm}$ with IZD of $19 \mathrm{~mm}$.

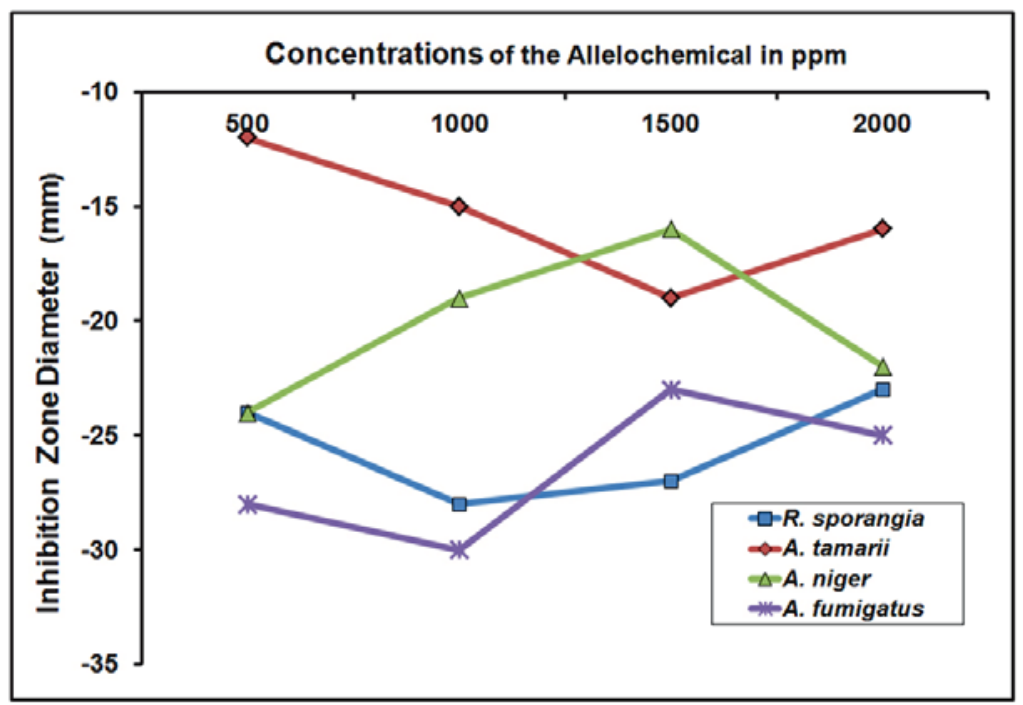

Figure 3. Inhibition Zone Diameter ( $\mathrm{mm}$ ) of MFEA at different concentrations on Aspergillus tamarii, Aspergillus niger, Aspergillus fumigatus and Rhizopus sporangia. 


\section{Antibacterial Assay of MFEA}

In the inhibition zone test, E. coli, $P$. aeruginosa and S. pneumonia revealed differential effects at different concentrations of purified MFEA (Figure 4). S. aureus exhibited stimulatory activity at all concentrations of MFEA with highest stimulation zone at 1500ppm (SZD-76mm) and minimum at $1000 \mathrm{ppm}$ (SZD-22mm). E. coli and P. aeruginosa showed inhibitory activity to MFEA and the degree of inhibition with increasing concentration.

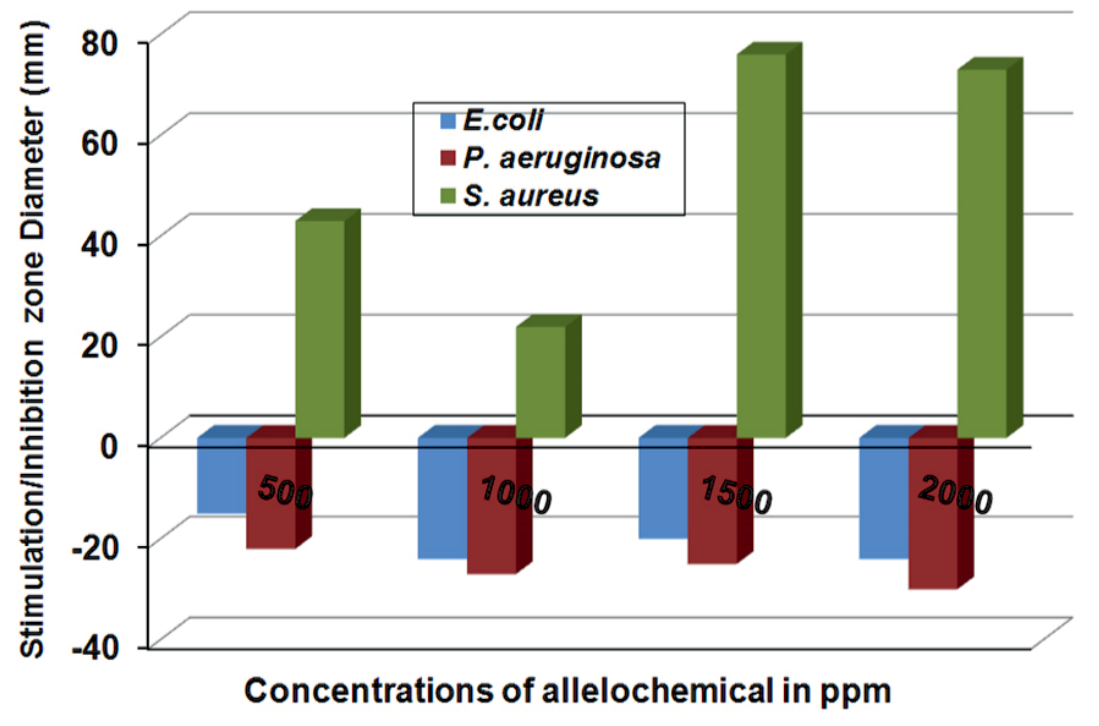

Figure 4. Antibacterial Assay of MFEA at different concentrations on Escherichia coli, Pseudomonas aeruginosa and Streptococcus aureus.

Inhibitory Activity (\%) of MFEA on Shoot and Root Length of Rice Seeds

MFEA at all concentrations showed inhibitory activity on rice (var. Latisal) seeds (Figure 5). In case of shoot length, inhibitory activity varies from $19 \%$ to $85.88 \%$. The Inhibitory activity in root length varies from $19 \%$ to $98 \%$. Results show that the inhibitory activity of MFEA on shoots and root lengths of rice seed vary. At 1600ppm of MFEA, maximum inhibitory activity of the shoot and root lengths of rice seeds were 
obtained at $85.88 \%$ and $98 \%$, respectively. Root length was more inhibited by MFEA compared to shoot length.
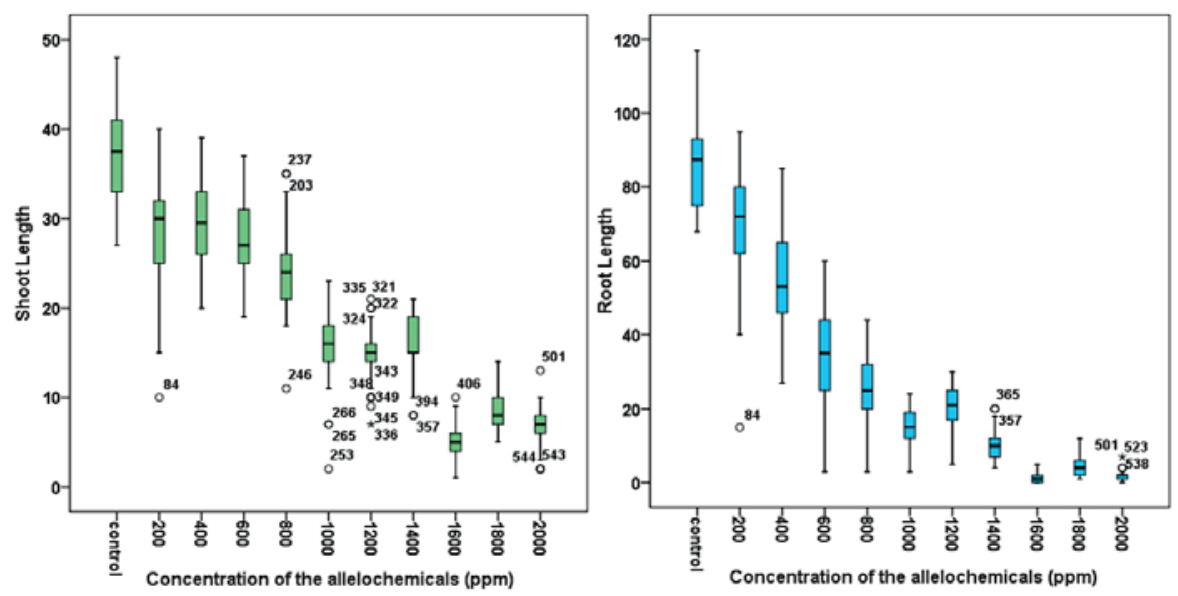

Figure 5. Effects of MFEA at different concentrations on shoot length and root length growth of rice (var. Latisal).

\section{STATISTICAL ANALYSIS}

To test the validity of the experimental results, the null hypothesis was assumed that the MFEA fraction has no effect on the rice seed germination. The descriptive statistics of the two dependent variables "root and shoot length" was done to see the profile of the independent variable "concentration of MFEA" on the complete data set. Significant differences in the mean in all variables were observed at significance level, $\mathrm{p} \leq 0.01$.

Table 1 shows that the inhibitory activity of MFEA on the germination of rice seeds $(\mathrm{N}=50)$ was lower than that of the control which exhibited a sharp inhibitory activity of MFEA.

The Post-Hoc test (Table 2) which represents the one-way analysis of variance (ANOVA). revealed that the variability of mean values of each variable is highly significant for each concentration (J) relative to the control (I). The mean difference in length was high in roots as compared to shoots. Hence, each concentration can be considered important for the inductive inference in the experiment. Furthermore, it can be concluded that the null hypotheses assumed is rejected. 
Table 1. Descriptive Statistics of shoot length and root length at different concentrations of MFEA on rice seed germination.

\begin{tabular}{|c|c|c|c|c|}
\hline Dependent variable & Concentration & Mean Inhibitory activity $(\mathrm{N}=50)$ & Std. Deviation & Std. Error \\
\hline \multirow{11}{*}{ Shoot Length } & control & 36.7200 & 5.38342 & .76133 \\
\hline & 200ppm & 28.6200 & 6.02000 & .85136 \\
\hline & 400ppm & 29.6600 & 4.57415 & .64688 \\
\hline & 600ppm & 27.4600 & 4.18554 & .59193 \\
\hline & $800 p p m$ & 24.2800 & 4.33326 & .61282 \\
\hline & $1000 \mathrm{ppm}$ & 15.6400 & 3.68538 & .52119 \\
\hline & $1200 p p m$ & 14.5600 & 2.95656 & .41812 \\
\hline & $1400 p p m$ & 15.7400 & 3.26896 & .46230 \\
\hline & $1600 \mathrm{ppm}$ & 5.1800 & 1.72248 & .24360 \\
\hline & $1800 \mathrm{ppm}$ & 8.4400 & 2.08160 & .29438 \\
\hline & $2000 \mathrm{ppm}$ & 7.0000 & 2.18529 & .30905 \\
\hline \multirow{11}{*}{ Root Length } & control & 86.8000 & 12.37179 & 1.74964 \\
\hline & $200 \mathrm{ppm}$ & 70.2200 & 14.30183 & 2.02258 \\
\hline & $400 \mathrm{ppm}$ & 55.1600 & 11.76185 & 1.66338 \\
\hline & $600 \mathrm{ppm}$ & 34.0200 & 12.77512 & 1.80667 \\
\hline & $800 p p m$ & 24.1800 & 9.85754 & 1.39407 \\
\hline & $1000 \mathrm{ppm}$ & 14.4400 & 5.61398 & .79394 \\
\hline & $1200 \mathrm{ppm}$ & 20.7400 & 5.38255 & .76121 \\
\hline & $1400 \mathrm{ppm}$ & 10.1600 & 3.98651 & .56378 \\
\hline & $1600 \mathrm{ppm}$ & 1.3800 & 1.38343 & .19565 \\
\hline & $1800 \mathrm{ppm}$ & 4.4800 & 2.76450 & .39096 \\
\hline & $2000 p p m$ & 1.7200 & 1.22957 & .17389 \\
\hline
\end{tabular}

These confer with the results graphically displayed by Box-plot which shows a distinct variation at mean levels for any randomly selected observations.

The scatter diagram reveals a nonlinear curve and plots. The curve estimation regression statistics resemble a cubic model (Figure.6) for both the dependent variables. Model that is defined by the equation $\mathrm{Y}=\mathrm{b} 0+(\mathrm{b} 1$ $* t)+(b 2 * t * * 2)+(b 3 * t * * 3)$. 
Evaluation of Bioactive Traits of Eclipta alba (L.) Hassk. Root Exudates

Table 2. Post Hoc comparisons of the mean shoot lengths and root lengths of rice.

\begin{tabular}{|c|c|c|c|c|c|}
\hline $\begin{array}{c}\text { Dependent } \\
\text { Variable }\end{array}$ & $\begin{array}{l}\text { (I) } \\
\text { Concentration } \\
\text { of the } \\
\text { allelochemical }\end{array}$ & $\begin{array}{c}\text { (J) } \\
\text { Concentration } \\
\text { of the } \\
\text { allelochemical }\end{array}$ & $\begin{array}{c}\text { Mean } \\
\text { Difference } \\
(\mathrm{I}-J)\end{array}$ & Std. Error & Probability \\
\hline \multirow{10}{*}{ Shoot Length } & \multirow{10}{*}{ Control } & 200ppm & $8.10000^{*}$ & .78050 & $<0.001$ \\
\hline & & 400ppm & $7.06000^{*}$ & .78050 & $<0.001$ \\
\hline & & 600ppm & $9.26000^{*}$ & .78050 & $<0.001$ \\
\hline & & 800ppm & $12.44000^{*}$ & .78050 & $<0.001$ \\
\hline & & $1000 \mathrm{ppm}$ & $21.08000^{*}$ & .78050 & $<0.001$ \\
\hline & & $1200 \mathrm{ppm}$ & $22.16000^{*}$ & .78050 & $<0.001$ \\
\hline & & $1400 \mathrm{ppm}$ & $20.98000^{*}$ & .78050 & $<0.001$ \\
\hline & & $1600 \mathrm{ppm}$ & $31.54000^{*}$ & .78050 & $<0.001$ \\
\hline & & $1800 \mathrm{ppm}$ & $28.28000^{*}$ & .78050 & $<0.001$ \\
\hline & & $2000 \mathrm{ppm}$ & $29.72000^{*}$ & .78050 & $<0.001$ \\
\hline \multirow{10}{*}{ Root Length } & \multirow{10}{*}{ Control } & 200ppm & $16.58000^{*}$ & 1.75164 & $<0.001$ \\
\hline & & 400ppm & $31.64000^{*}$ & 1.75164 & $<0.001$ \\
\hline & & 600ppm & $52.78000^{*}$ & 1.75164 & $<0.001$ \\
\hline & & 800ppm & $62.62000^{*}$ & 1.75164 & $<0.001$ \\
\hline & & $1000 \mathrm{ppm}$ & $72.36000^{*}$ & 1.75164 & $<0.001$ \\
\hline & & $1200 \mathrm{ppm}$ & $66.06000^{*}$ & 1.75164 & $<0.001$ \\
\hline & & $1400 \mathrm{ppm}$ & $76.64000^{*}$ & 1.75164 & $<0.001$ \\
\hline & & $1600 \mathrm{ppm}$ & $85.42000^{*}$ & 1.75164 & $<0.001$ \\
\hline & & $1800 \mathrm{ppm}$ & $82.32000^{*}$ & 1.75164 & $<0.001$ \\
\hline & & $2000 \mathrm{ppm}$ & $85.08000^{*}$ & 1.75164 & $<0.001$ \\
\hline
\end{tabular}

The mean difference is significant at the 0.01 level based on Scheffe's test. 

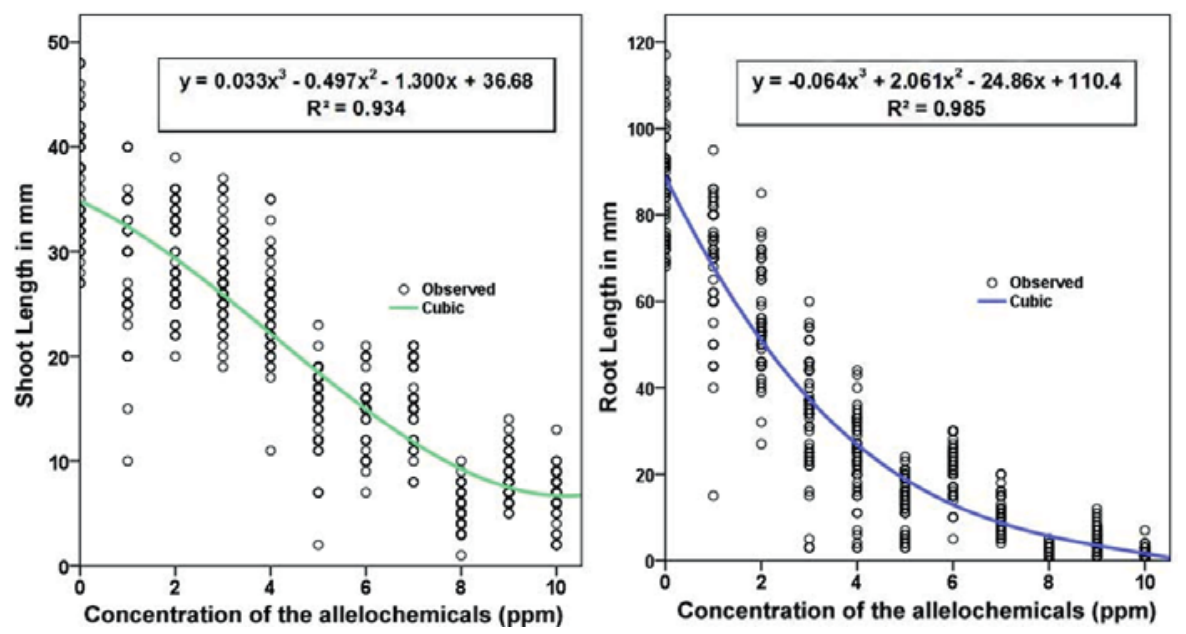

Figure 6. Cubic Model of the Curve Estimation of Shoot length and root length.

\section{DISCUSSION}

Plants are the invaluable source of pharamaceutical and agricultural products. A large numbers of plants are screened in order to replace hazardous chemicals with relatively cheap and safe to use herbal medicines. The intensive pharmacological profile of $E$. alba promises to be a plant based alternate to synthetic drugs particularly when invasiveness is one of its growth trait. In our findings the methanol fraction of the plant root exudates (MFEA) which has been isolated up to $99.9 \%$ purity, was found to possess the trait of a biopesticide. The MFEA fraction was found to be phytotoxic against shoot and root length of rice seeds after germination. Noteworthy, the highest dilution (2000 ppm) was found to promote seed dormancy. The comparative data analysis shows statistical significance at all concentrations with respect to control. The regression curve plots a cubic model for both root and shoots growth with concentration taken as the independent variable. The boxplot synchronizes the effect of the compound on the growth of the radical and the plumule. The fraction also shows a pronounced effect on the microbes both as an antimicrobial agent as well alarms stimulation. The methanol fraction showed inhibitory activity against multidrug resistant bacterial species such as $P$. aeruginosa and uropathogen E. coli at all concentrations from 500ppm to $2000 \mathrm{ppm}$. However $S$. aureus showed a reverse activity with stimulatory activity at all 
concentrations. The maximum stimulation was seen at $1500 \mathrm{ppm}$ with a zone diameter of $76 \mathrm{~mm}$. This exerts selectivity of its utilization in various dermatological products. Additively, the MFEA fraction was found to be an antifungal agent against three aspergillosis causing fungus $A$.niger, $A$. tamari and $A$. fumigatus. The compound showed a strong inhibition against $R$. sporangia which causes fruit rot or even human complications. The microbes chosen for this study were based on clinical relevance and are found in a broad range of host and presents serious threat to cosmetic and food industry. The findings thus assure the potent allelopathic activity and ethnomedicinal properties of root exudates from E. alba.

\section{ACKNOWLEDGMENT}

We are privileged to convey our sincere gratitude to our respected Director, Prof. Bimal Roy, Indian Statistical Institute, for providing laboratory facilities and financial support. We are indebted to Prof. Subrata Roy, Prof-in-Charge, Biological Sciences Division and Prof. Joydev Chattopadhyay, Head, Agricultural and Ecological Research Unit, Indian Statistical Institute, for their affectionate encouragement, valuable advice and enormous laboratory facilities. We also thank Mr. Bharat Bhanderi, Mrs Sankarirani Saha of the Agricultural and Ecological Research Unit, Indian Statistical Institute, for their valuable assistance in the laboratory and field.

\section{REFERENCES}

BISWAS, S.M., BHATTACHARYA, S., CHANDA, S. and KUMAR, L., 2009. 3, 4dihydroxy benzyl ester derivative, a potent biopesticide isolated from leaves of Tectona grandis, L., Biopesticide Intl., 5: 24-34.

DAYAN, F.E., ROMAGNI, J.G. and DUKE, S.O. 2000. Investigating the mode of action of natural phytotoxins. J. Chem Ecol., 26:2079-2094.

DUKE, S.O., DAYAN, F.E., ROMAGNI J.G. and RIMANDO, A.M. 2000. Natural products as sources of herbicides: current status and future trends. Weed Res. 10:99-111.

EINHELLIG, F.A. 2004. Mode of allelochemical action of phenolic compounds; in Allelopathy, chemistry and mode of action of allelochemicals (eds) MACIAS F.A., GALINDO J.C.G., MOLINILLO J.M.G. and CUTLER H.G. (Boca Raton: CRC Press). 
68

Chakraborty et al.

INDERJIT, S. 1996. Plant phenolics in allelopathy. Botanical Review 62:186-202.

INDERJIT, S. and MUKERJI, K.G. 2006. Discovery and evaluation of natural product based fungicides for Disease Control of Small Fruits; Allelochemicals: Biological Control of Plant Pathogens and Diseases, Springer, Dordrecht, Netherlands.

KHANH, T.D., CHUNG, I.M., XUAN, T.D. and TAWATA, S. 2005. The Exploitation of Crop Allelopathy in Sustainable Agricultural Production.J. Agron. Crop Sci. 191:172-184.

MITHUN, N.M., SHASHIDHARA, S. 2011. Eclipta alba (L.) A review on its phytochemical and pharmacological profile. Pharmacologyonline 1:345-357.

MANDAL, S. 2001. Allelpathic activity of root exudates from Leonurus sibiricus L. (Raktodrone). Weed Biol. and Mgt., 1:170-175.

RICE, E.L. 1984. Allelopathy 2nd edition, Orlando: Academic Press. 